\title{
Restorasi Fiber Reinforced Composite Pada Gigi Premolar Pertama Kanan Mandibula Pasca Perawatan Saluran Akar
}

\author{
Intan Dhamayanti* dan Tunjung Nugraheni** \\ * Program Studi Konservasi Gigi PPDGS Fakultas Kedokteran Gigi Univeristas Gadjah Mada \\ **Bagian Konservasi Gigi Fakultas Kedokteran Gigi Univeristas Gadjah Mada \\ *J Denta Sekip Utara, Yogyakarta, e-mail: intandhamayanti@yahoo.com
}

\begin{abstract}
ABSTRAK
Gigi yang telah dilakukan perawatan saluran akar membutuhkan restorasi yang tepat untuk mencegah terjadinya fraktur. Restorasi menggunakan fiber reinforced composite (FRC) memiliki resistensi yang tinggi terhadap fraktur dan estetiknya memuaskan. Laporan kasus ini bertujuan melaporkan restorasi menggunakan FRC pada gigi premolar pertama kanan mandibula pasca perawatan saluran akar. Pada kasus ini, pasien wanita 35 tahun, gigi premolar pertama kanan mandibula mengalami nekrosis pulpa. Untuk mengatasi kasus ini dilakukan perawatan saluran akar dengan metode crown down dan obturasi dengan single cone. Restorasi menggunakan FRC dibuat sebagai restorasi akhir. Kesimpulan penanganan kasus, restorasi menggunakan FRC dapat menjadi pilihan restorasi pada gigi premolar pertama kanan mandibula pasca perawatan saluran akar.
\end{abstract}

Maj Ked Gi. Juni 2013;20(1): 65. 70.

Kata kunci : FRC (fiber reinforced composite), restorasi,

ABSTRACT: Fiber Reinforced Composite Restoration on Right Mandibular First Premolar Tooth after Root Canal Treatment. Endodontically treated tooth requires precise restoration that can prevent fracture. Restoration using fiber reinforced composite (FRC) has high resistance to the fracture and aesthetical satisfaction. This case report aims to describe the restoration using FRC on right mandibular first premolar tooth after root canal treatment. In this case, the patient was a 35 year-old woman who suffered from pulp necrosis on her right mandibular first premolar tooth. To treat this case, root canal treatment with crown down method and single cone's obturation was done. Restoration using FRC is made as the final restoration. From treatment, it can be concluded that restoration using FRC can be an option for restoration of right mandibular first premolar tooth after root canal treatment. Maj Ked Gi. Juni 2013;20(1): 65 - 70.

Keywords :FRC (fiber reinforced composite), restoration

\section{PENDAHULUAN}

Restorasi gigi bertujuan untuk mengem-balikan fungsi fisiologis dan fungsi estetis gigi.Pasca perawatan saluran akar,gigi memerlukan restorasi akhir yang memiliki retensi dan resistensi yang baik agar restorasi bertahan lama. Besarnya karies serta banyaknya pengambilan jaringan keras gigi saat melakukan perawatan saluran akar, terutama saat preparasi intra koronal dapat melemahkan jaringan keras gigi yang masih ada dalam menahan tekanan pengunyahan. Keadaan ini dapat mengurangi kekuatan gigi pada saat pembuatan restorasi akhir. Kurangnya retensi dan resistensi pada pembuatan restorasi akhir akan meng-akibatkan kegagalan restorasi seperti fraktur mahkota atau lepasnya restorasi. ${ }^{1}$
Restorasi akhir gigi pasca perawatan saluran akar merupakan bagian integral dari kunci keberhasilan perawatan. Gigi yang telah dilakukan perawatan saluran akar menjadi mudah fraktur karena gigi kehilangan integritas, kelembaban dan kekerasan dentin. ${ }^{2}$ Perencanaan restorasi akhir biasanya ditentukan sebelum perawatan saluran akar. Operator harus mengetahui jenis restorasi akhir apa yang akan dibuat agar mendapatkan hasil perawatan yang optimal. ${ }^{1}$ Tidak semua gigi pasca perawatan saluran akar membutuhkan restorasi dengan mahkota penuh. Jika sisa jaringan keras gigi masih banyak, maka gigi dapat direstorasi secara direk menggunakan resin komposit untuk memperoleh hasil yang memuaskan. ${ }^{3}$ 
Faktor-faktor yang harus diperhatikan untuk mencapai keberhasilan restorasi akhir setelah perawatan saluran akar antara lain perbandingan akar dan mahkota gigi yaitu berkisar 3:2 antara akar dan mahkota gigi serta jaringan keras gigi yang tersisa. Gigi setelah perawatan saluran akar, biasanya telah banyak kehilangan jaringan pendukungnya sehingga mempengaruhi retensi dan resistensi pada restorasi akhir. ${ }^{1}$

Resistensi terhadap fraktur berkurang pada gigi dengan preparasi kavitas yang luas. Gigi posterior khususnya premolar memiliki bentuk anatomi dengan resiko fraktur yang tinggi akibat tekanan mastikasi. Gaya mastikasi yang terjadi saat pengunyahan pada gigi premolar adalah gaya vertikal yang memudahkan berpisahnya tonjol bukal dan tonjol lingual pada gigi dengan resistensi yang rendah terhadap fraktur. Restorasi akhir baik restorasi direk maupun indirek harus dapat memperkuat sisa jaringan keras gigi yang masih ada dan dapat mengembalikan fungsi gigi. ${ }^{4}$

Seiring perkembangan teknologi baik dalam material maupun teknik restorasi pada bidang konservasi gigi, penggunaan resin komposit sebagai restorasi gigi posterior banyak digunakan karena memiliki banyak keuntungan seperti preparasi jaringan keras gigi minimal, waktu pengerjaan singkat, warna restorasi seperti gigi asli dan biaya lebih terjangkau. ${ }^{5}$ Restorasi pada gigi posterior menerima beban mastikasi yang tinggi sehingga resin komposit yang digunakan harus memiliki ketahanan terhadap fraktur dan pemakaian serta dapat memberi efek radiopak yang baik pada gambaran radiografi. Jenis resin komposit yang direkomendasikan untuk restorasi gigi posterior adalah resin komposit packable. Volume bahan pengisi resin komposit packable antara 66-70\%. Komposisi bahan pengisi yang tinggi tersebut mengakibatkan resin komposit packable dapat mengurangi pengerutan selama polimerisasi. Resin komposit packable memiliki kekentalan atau viskositas yang tinggi, hal ini mengakibatkan komposit sulit mencapai adaptasi marginal sehingga para klinisi biasanya menggunakan komposit flowable pada dasar kavitas sebagai lapisan pertama untuk meningkatkan adaptasinya. ${ }^{6}$
Penggunaan bahan pelapis seperti komposit flowable dan fiber polyethylene pada dasar kavitas, dapat mengurangi pengerutan resin komposit dan menahan tekanan mastikasi. Aplikasi fiber dalam resin komposit dapat meningkatkan resistensi terhadap fraktur dan memperkuat restorasi terutama pada gigi dengan kavitas yang luas seperti pada kavitas kelas 11. ${ }^{7}$ Fiber dapat meningkatkan sifat mekanis resin komposit dan mengurangi tekanan eksternal sehingga memperkecil resiko fraktur karena fiber dapat menyalurkan tekanan ke jaringan gigi sekitarnya. Fiber yang digunakan menjadi FRC adalah fiber glass dan fiberpolyethylene. Fiber glass lebih sering dipakai dalam pekerjaan laboratorium sedangkan fiber polyethylene banyak digunakan sebagai pasak yang dibuat sendiri (pabricated atau chairside application).

Fiber Reinforced Composite (FRC) memilki flexure strength dan fatique strength yang tinggi, modulus elastisitas yang mendekati dentin, sifat estetis baik, tidak mengalami korosif, biokompatibel serta dapat mendistribusikan tekanan lebih merata saat mendapat tekanan sehingga dapat mencegah fraktur. ${ }^{8}$ Penambahan fiber pada dasar restorasi MOD gigi setelah perawatan saluran akar menyebabkan resistensi terhadap fraktur yang lebih tinggi dibanding restorasi tanpa penambahan fiber. ${ }^{9}$ Tujuan dari penulisan ini bertujuan untuk membahas restorasi menggunakan FRC pada gigi premolar pertama kanan mandibula pasca perawatan saluran akar

\section{STUDI KASUS}

Seorang pasien perempuan berusia 35 tahun datang ke Klinik Spesialis Konservasi RSGM Prof Soedomo dengan keluhan gigi belakang kanan bawah ingin ditambal. Dua bulan lalu gigi pernah sakit dan ditambal di puskesmas dengan tambalan sementara. Saat ini gigi tidak terasa sakit, pasien ingin giginya ditambal tetap (Gambar 1).

Pada pemeriksaan klinis terlihat tumpatan sementara di bagian distal gigi premolar pertama kanan mandibula. Setelah tumpatan sementara dibuang, terlihat kavitas dengan pulpa terbuka. 


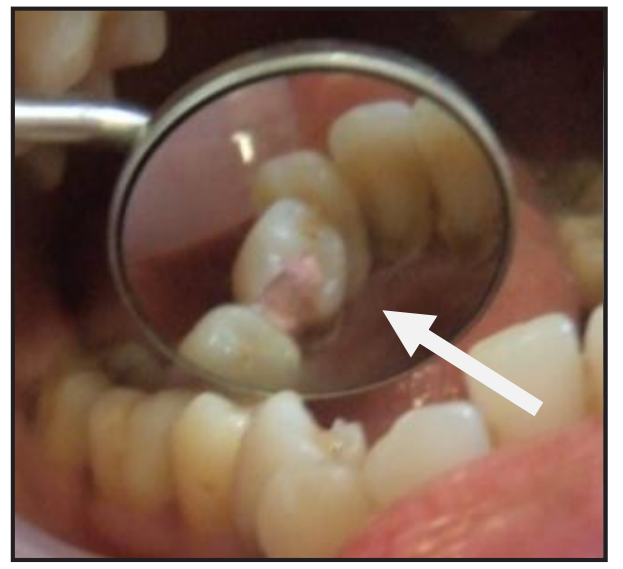

(A)

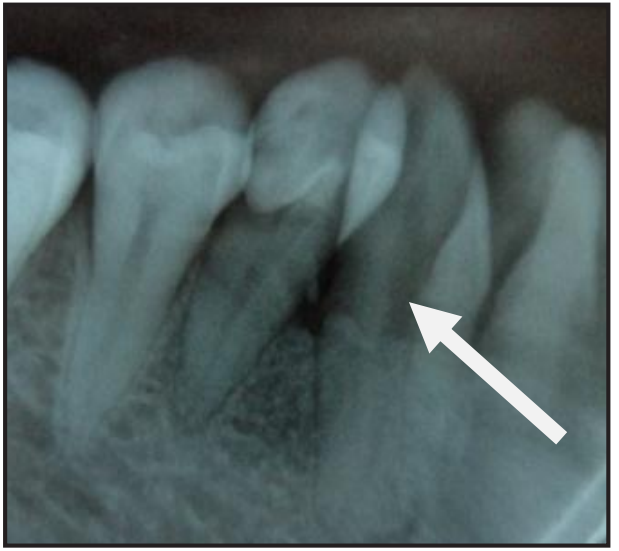

(B)

Gambar 1. (A) Foto klinis gigi 44 sebelum perawatan; (B) Foto rontgen sebelum perawatan

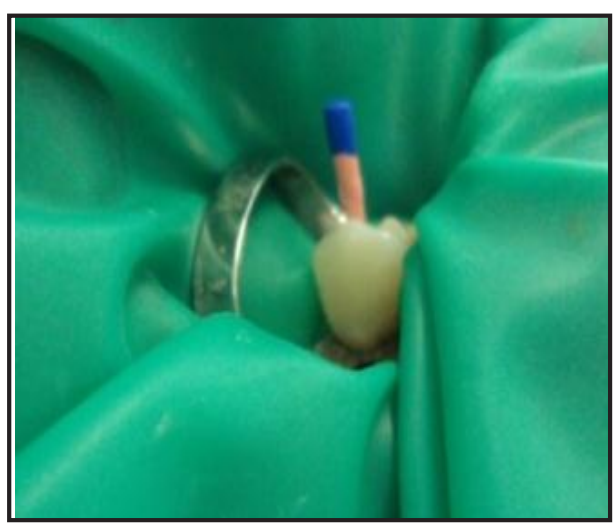

(A)

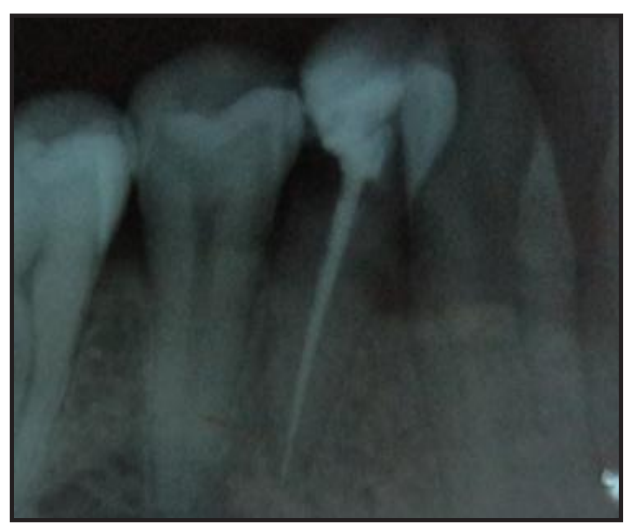

(B)

Gambar 2. (A) Obturasi gigi 44; (B) Foto rontgen pasca obturasi

Pada pemeriksaan termal dingin, perkusi dan palpasi menunjukkan respon yang negatif, gigi tidak mengalami mobilitas. Pemeriksaan radiografis terlihat kavitas mencapai kamar pulpa. Saluran akar lurus dan tidak terlihat adanya area radiolusen pada bagian periapikal. Diagnosis gigi 44 karies profunda dengan nekrosis pulpa. Perawatan yang akan dilakukan adalah perawatan saluran akar satu kali kunjungan dan restorasi akhir dengan resin komposit direk karena jaringan keras gigi yang ada masih memungkinkan untuk dilakukan restorasi resin komposit secara direk.

Kunjungan pertama dilakukan pemeriksaan subjektif, pemeriksaan objektif dan radiografis kemudian ditentukan diagnosis dan rencana perawatan, dokumentasi sebelum perawatan serta penandatanganan informed consent. Perawatan saluran akar dilakukan menggunakan file protaper handuse (protaper yang digerakkan secara manual menggunakan tangan) dengan metode crowndown (preparasi saluran akar dimulai dari bagian koronal saluran akar dilanjutkan ke bagian apikal).Obturasi saluran akar teknik single cone menggunakan gutta percha dan sealer resin (Gambar 2).

Kunjungan kedua, pemeriksaan subyektif tidak ada keluhan. Pemeriksaan obyektif, tumpatan sementara masih baik, perkusi dan palpasi negatif, pemeriksaan radiografis tidak terlihat kelainan periapikal. Penyesuaian warna menggunakan Vita lumin shade guide warna A2 dilanjutkan preparasi kavitas kelas II. Preparasi bagian oklusal dilakukan untuk memperoleh fresh cutting enamel. Bagian 
proksimal dibuat counter bevel menggunakan micro preparation bur bentuk flame serta pada gingival margin digunakan enamel hatchet dan micro preparation bur. Selanjutnya gutta percha diambil $3 \mathrm{~mm}$ dari orifis ke arah apikal menggunakan plugger yang dipanaskan. Hal ini dimaksudkan untuk menempatkan FRC guna menambah retensi restorasi.

Kavitas dietsa dengan asam fosfat selama 15 detik, setelah itu dicuci dan dikeringkan (moist). Selanjutnya aplikasi bahan bonding dan dihembuskan udara secara tidak langsung serta perlahan-lahan kemudian diaktivasi sinar selama 20 detik. Pita FRC (Construct, Kerr) dipotong 2,5 cm kemudian dibasahi bahan bondin $\mathrm{g}$ dan diberi flowable resin dengan cara ditekan-tekan menggunakan instrument

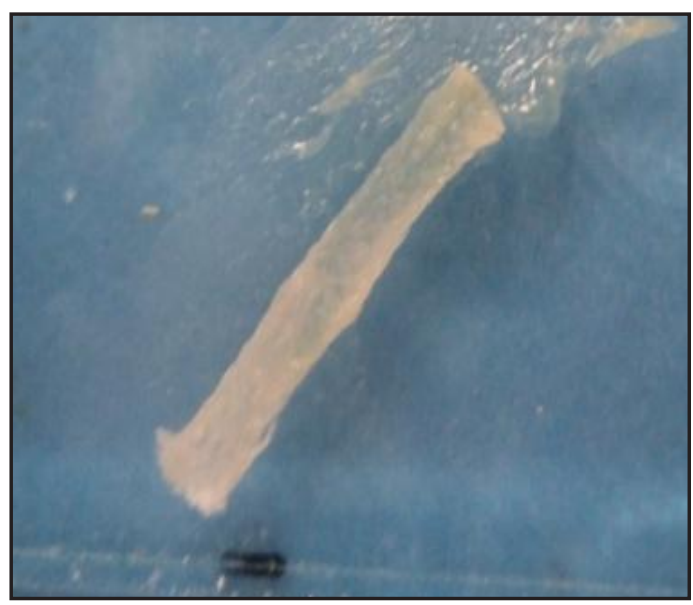

(A) plastis hingga semua bagian pita FRC basah oleh resin. Pemasangan matriks greater curve pada gigi 44 kemudian resin komposit flowable diaplikasikan pada dasar kavitas, selanjutnya pita FRC yang telah siap dimasukkan ke dalam kavitas menggunakan pinset khusus, ditekan ke arah orifis menggunakan plugger dan sisanya ditekan ke dinding distal serta mesial, kemudian disinar 20 detik (gambar 3).

Aplikasi bahan resin komposit packable dilakukan secara berlapis dengan ketebalan $2 \mathrm{~mm}$ setiap lapisan kemudian diaktivasi dengan sinar (light cure unit) selama 20 detik. Penumpatan dilakukan sampai restorasi terbentuk sesuai dengan anatomi gigi. Setelah restorasi resin komposit selesai, dilakukan pengecekan oklusi dan artikulasi menggunakan articulating paper kemudian dilakukan finishing

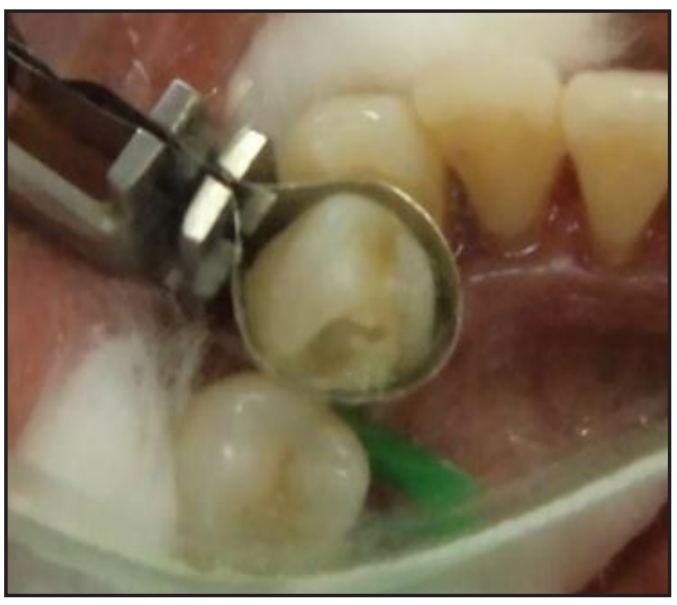

(B)

Gambar 3. (A) FRC setelah dibasahi resin; (B) aplikasi FRC pada kavitas

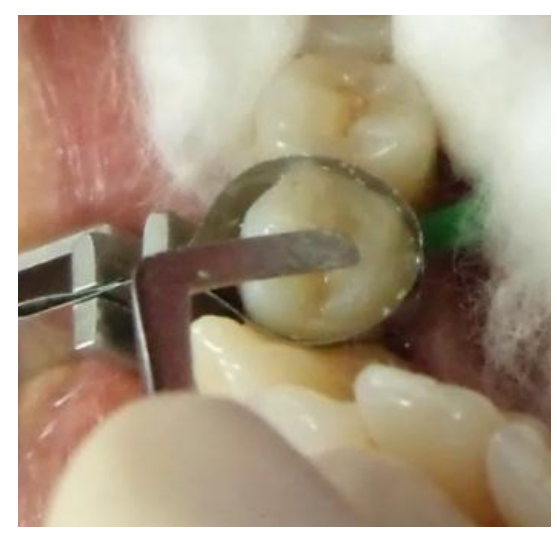

(A)

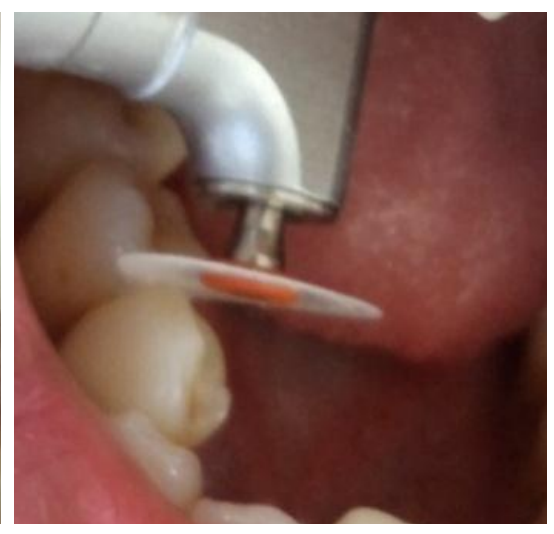

(B)

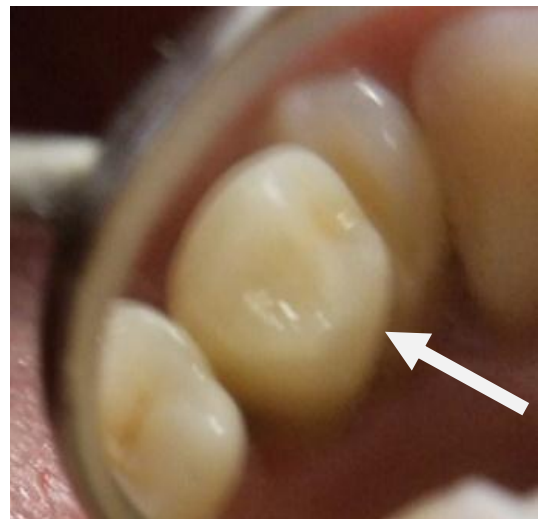

(C)

Gambar 4. (A) Aplikasi resin komposit packable, (B) Polishing, (C) hasil akhir restorasi 
dan polishing dengan menggunakan optidisc dan optishine (Kerr) (gambar 4).

Kunjungan ketiga, pemeriksaan subyektif tidak ada keluhan dan pasien merasa puas dengan hasil perawatan. Pemeriksaan obyektif perkusi, palpasi dan mobilitas negatif, restorasi resin komposit dalam keadaan baik, warna restorasi gigi premolar pertama kanan mandibulas ama dengan warna gigi lainnya. Pasien diinstruksikan untuk selalu menjaga kebersihan giginya dan kontrol setelah 6 bulan.

\section{PEMBAHASAN}

Gigi pasca perawatan saluran akar memiliki kelembaban internal yang rendah karena kandungan airnya sedikit dibanding gigi vital sehingga gigi menjadi rapuh dan mudah fraktur. Pengurangan dentin saat melakukan perawatan saluran akar juga akan melemahkan jaringan keras gigi yang masih ada. ${ }^{10} \mathrm{Hal}$ ini menyebabkan restorasi gigi pasca perawatan saluran akar harus direncanakan dengan mempertimbangkan retensi dan resistensi yang kuat agar restorasi akhir pasca perawatan saluran akar dapat mempertahankan fungsi gigi dalam jangka waktu lama. ${ }^{8}$ Jenis restorasi yang dapat digunakan tergantung pada sedikit banyaknya jaringan keras gigi yang tersisa. Restorasi pada gigi pasca perawatan saluran akar dapat menggunakan restorasi direk dengan amalgam atau resin komposit maupun restorasi indirek dengan logam atau porselen. ${ }^{4}$

Perubahan paradigma perawatan ke arah intervensi minimal disertai perkembangan dalam bidang material restorasi, menyebabkan tingginya penggunaan resin komposit sebagai material restorasi. Jaringan keras gigi tidak dapat beregenerasi sehingga tindakan konservatif dengan pengambilan jaringan keras gigi seminimal mungkin adalah yang terbaik. Pada kasus ini, restorasi resin komposit direk digunakan dengan pertimbangan sisa jaringan keras gigi yang ada masih banyak dan memungkinkan direstorasi resin komposit secara direk. Keuntungan restorasi resin komposit direk antara lain preparasi gigi yang minimal sehingga dapat mempertahankan sisa jaringan keras gigi, waktu pengerjaan singkat dan biaya terjangkau. ${ }^{5}$ Indikasi restorasi resin komposit direk adalah gigi dengan kehilangan jaringan keras gigi minimal, mudah pengaplikasiaannya dan prognosis yang tidak meyakinkan sehingga membutuhkan restorasi yang semipermanen. ${ }^{3}$ Syarat preparasi kavitas memiliki lebar $1 / 3$ jarak antar tonjol dan lebar boks proksimal tepat pada lebar maksimal 1/3 bukal lingual. ${ }^{11}$

Resin komposit yang digunakan untuk melapisi fiber memainkan peranan penting karena mempengaruhi ketahanan terhadap pemakaian serta nilai estetis restorasi akhir. Pada kasus ini, resin komposit yang digunakan adalah resin komposit flowable dan packable. Resin komposit flowable digunakan pada dasar kavitas. Resin komposit flowable berfungsi untuk meningkatkan adaptasi antara gigi dengan restorasi sehingga dapat meningkatkan integritas restorasidan memungkinkan efisiensi penyaluran stres yang akan menahan fraktur pada restorasi komposit. Resin komposit packable memiliki jumlah filler yang banyak sehingga pengerutan polimerisasinya rendah, mudah dimanipulasi, ketahanan terhadap aus serta tekanan kunyah tinggi sehingga cocok untuk restorasi gigi posterior.

Fiber Reinforced composite (FRC) terbuat dari karbon atau kumpulan serat silika berdiameter 7-10 $\mu \mathrm{m}$ yang memiliki berbagai variasi bentuk seperti jalinan pita, anyaman atau paralel (unidirectional). FRC terdiri dari komponen fiber yang terbenam dalam matrik polimer resin sehingga fiber terikat menjadi satu kesatuan. Fiber berfungsi sebagai penguat sedangkan matriks berfungsi untuk menyalurkan tekanan diantara fiber serta melindungi fiber dari kerusakan mekanis dan lingkungan. ${ }^{12}$ Fiber harus penuh terlapisi oleh resin sehingga polimer resin dapat berkontak dengan setiap permukaan fiber supaya mencapai perlekatan yang adekuat antara fiber dengan matriks polimer resin.

FRC berbentuk pita digunakan sebagai bahan pelapis pada dasar kavitas. Hal ini untuk meningkatkan resistensi terhadap fraktur dan memperkuat restorasi karena modulus elastisitas FRC hampir sama dengan modulus elastisitas dentin sehingga mengurangi resiko terjadinya fraktur. FRC memiliki kemampuan untuk meredam tekanan dan menyalurkannya ke sisa jaringan gigiserta dapat 
berfungsi sebagai penguat karena FRC memiliki modulus elastisitas yang tinggi, flexural strength serta tensile strength tinggi..FRC tidak mengalami korosif, biokompatibel serta memenuhi unsur estetis karena memiliki warna translusen yang menyerupai warna gigi. ${ }^{13}$

Kombinasi resin komposit dengan FRC dapat diaplikasikan pada restorasi gigi posterior karena fiber akan menambah kekuatan restorasi resin komposit. Fiber akan mengurangi tekanan pada resin komposit serta menyalurkannya ke jaringan gigi sekitarnya sehingga dapat mengurangi terjadinya fraktur. Menurut penelitian, rata-rata keberhasilan klinis pada gigi premolar pasca perawatan saluran akar yang menggunakan restorasi resin komposit dan FRC sama dengan restorasi mahkota penuh Porselen Fused Metal(PFM). ${ }^{14}$ Belli dkk. ${ }^{9}$ meneliti pengaruh penggunaan komposit flowable dengan dan tanpa fiber, menyebutkan bahwa penggunaan fiber dan komposit flowable menghasilkan resistensi terhadap fraktur yang lebih tinggi dibanding bila hanya menggunakan komposit flowable.

\section{KESIMPULAN}

Restorasi menggunakan fiber reinforced composite memberikan hasil yang memuaskan secara estetik maupun fungsional pada gigi premolar pertama kanan mandibula pasca perawatan saluran akar.

\section{DAFTAR PUSTAKA}

1. Tarigan R. Perawatan pulpa gigi. Jakarta: EGC; 1994.

2. Deliperi S, Bardwell DN. Two year clinical evaluation of non vital tooth whitening and resin composite restoration. J. Esthet Restor. 2005; 17(6): 369-379.

3. Walton R, Torabinejad. Prinsip dan Praktek IImu Endodonsi. Ed 4. Jakarta: EGC; 2009.
4. Cobankara FK, Unlu N, Cetin AR, Azkan HB. The effect of different restoration technique on the fracture resistance of endodontically treated molar. Oper Dent. 2008; 3(5):526-533.

5. Mondelli RFL, Ishikiriam SK, Filho O, Mondelli J. Fracture resistance of weaked teeth restoration with condenbale resin with and without cusp coverage. J. Appl oral Sci. 2008; 17 (3) : 161-165.

6. Heymann HO, Swift EJ, Ritter AV. Sturdevant's art and science of operative dentistry. Ed 6. Mosby Elsevier Inc; 2013.

7. $\mathrm{Xu} H \mathrm{HH}$, Schumacher GE, Eichmiller FC, Peterson RC, Antonucci JM, Mueller HJ. Continouos fiber perform reinforcement of dental resin composite restoration. Dent mater. 2003; 19 (60): 523-530.

8. Cheung W. A review of the management of endodontically treated teeth; post, core and the final restoration. J Am Dent Ass. 2005; (136): 611619.

9. Belli S, Erdemir A, Ozcopur, Eskitascioglu G. The effect if fiber insertion on fracture resistance of root filled molar teeth with mod preparation restored with composite. Int endod J. 2005; (38): 73-80.

10. Ingle B. Endodontics. Ed 5. Hamilton London: BC Decker Inc; 2002.

11. Marchan SM, Coldero L, White D, Smith WA, Rafeek R. Cusp fracture resistance of weakened teeth restored with condensable resin with and without cusp coverage. J Appl Oral Sci. 2009; 17(3): 161-165.

12. Lasilla L, Tanner J, Bell AM, Narva K \& Vallitu. Flexural properties of fiber reinforced root canal posts, Dental Material. 2004; (20): 29-36.

13. Valittu PK. Acrylic resin-fiber composite part 1; the effect of fiber concentration on fracture resistance. J Prosthet dent. 1993; (63): 251-257.

14. Manocci F, Sherriff $M$, Watson TF \& Ford TR. Three years clinical comparison of survival of endodontically treated teeth restored with either full cast coverageor with direct composite restoration. J Prosth Dent. 2002; (88): 297-301. 